\title{
Highly Effective Learning and Application Thereof to Roma Pupils Elementary Education System in Slovakia
}

\author{
Michal Pankevič
}

\section{ABSTRACT}

Fragmentation of educational content, caused by the scientific-subject structure of the traditional school, in many cases inhibits the motivation and activity of pupils in the educational process. The saturation of knowledge, skills, and competencies - especially of roma pupils in elementary education - is thus underestimated and in many cases lags behind the standard level of the majority of pupils. It follows that the effectiveness of elementary education-especially for roma pupilsincreases proportionally with the relevancy and a certain attractiveness of teaching organizational forms and methods whereby it is implemented. One of the alternative solutions for increasing the level of effectiveness of elementary education (inter alia) of roma pupils is the pedagogical concept of highly effective learning based on an integrated thematic teaching system. It turns out that in this context this concept can be considered as a motivating and activating element expanding the knowledge level of pupils, while at the same time enriching them educationally. It integrates strategies that are focused on the discovery, action, cooperative, authentic, and confluent learning of pupils. This paper deals with the issue of the educational concept of highly effective learning in terms of its application to roma pupils in the first grade of elementary education. It presents the current results of a pedagogical experiment as the elementary empirical method of research in the field of social climate, creativity, and the level of knowledge of pupils within the elementary first-grade educational environment.

Keywords: Brain-compatible environment, cognitive development, creativity, highly effective learning, roma pupil, social climate.
Published Online: November 13, 2021

ISSN: $2736-4534$

DOI : 10.24018/ejedu.2021.2.6.201

M. Pankevič*

Faculty of Education, Catholic University, Ružomberok, Slovakia.

(e-mail: michal.pankevic@ku.sk)

*Corresponding Author

\section{THEORETICAL DETERMINANTS}

Education and learning are a phenomenon with its own genesis and laws, which are shifting perpetually following the current social needs. Education in current social conditions follows the trends of the European cultural environment. The educational process should thus take into account historical and cultural traditions, but at the same time, it should meet the present requirements and the future needs. Education is part of continuous development ignited by the search for effective ways to develop the personality of each individual in society.

Since the 1960s, the school has, in essence, been criticized for failing to meet the tasks that are expected of it in this rapidly changing society. The response to this criticism is the emergence of a number of theoretical concepts - practical experiments in particular — which aimed to address this situation and seek new ways to improve school education. 
This situation is followed by the trend of post-1989 intensive development of innovative concepts of education (Brestenská et al., 2019).

The gradual transition from socialization to personalization today - more than ever — is aimed at finding concrete procedures that would be effective in terms of the complexity of the development of the 'sui generis' personality. The development of each person's personality is realized primarily by deliberately inducing activities, through situations and tasks of a divergent nature, and solving problems, and using such methods, forms, and means that eliminate the formation of thought stereotypes. The current development of science, technology, and society as a whole also comes up with the need to reflect on existing concepts of education and their justification in shifting social, political, and economic conditions.

In the last three decades, the need to humanize and democratize education has been strongly emphasized. Despite the efforts made so far, the school system of many (inter alia) European countries is still focused on memory learning mastering the amount of knowledge, and less on thinking, experiencing, motivating, and value orientation of pupils. In real life, a successful individual is expected to be able to think critically and evaluate and use creativity, imagination, cooperation, conceptualism, and perseverance. Such a concept brings the vision of a person who knows their abilities, can apply them in real life, and is able to live happily and fully.

The issue of this paper is Highly Effective Learning (the 'HE Learning') and its impact on the effectiveness of Roma pupils' education. It is an educational concept based on the platform of Integrated Thematic Teaching and is one of the so-called modern alternative schools. Since its inception in the 1980s (invented by Susan Kovalik and Karen D. Olsen), it has been significantly influencing pedagogical reality in a global context for more than three decades. It is a pedagogical model of education that - through its innovation and humanistic orientation, holistic approach, and holistic perception of problems, facts, and phenomena-has a significant potential for achieving positive changes in the educational reality at the first grade of elementary education. The learning basis lies in the creation of opportunities to gain their own experience, experience with the learning topic most often through projects, field trips (i. e. being there and done that), an annual topic, and sub-topics. The program is being gradually introduced into the classroom (school) (Kovalik \& Olsen, 1996).

It follows from the fact that the author of the HE Learning Susan Kovalik has many years of research and teaching experience and at the same time managed to achieve very positive results with pupils from socially disadvantaged backgrounds (low-achieving students, immigrant children in the US), we assume that the educational concept analyzed will be effective in the Roma pupil elementary education within the Slovak school system.

\section{Methodological Determinants}

Objective reality has various questions that cannot be answered immediately. The need to seek an answer requires a theoretical and pragmatic effort to focus on new knowledge.
Several research questions may arise, but through abstraction of the main components and relationships, it is possible to formulate one's own research problem (Darák \& Krajčová, 2020).

When planning the research, we asked ourselves several research questions related to the subject matter. By further correcting and refining them, we came to the formulation of the following research problem.

\section{A. Research Problem}

What impact will the implementation of the HE Learning educational program have on the effectiveness of the Roma pupils' education?

\section{B. Research Project Objectives}

The principal aim of the research is experimental verification of the effectiveness of the HE Learning model for increasing the effectiveness of education of Roma pupils in the first-grade of elementary school.

Sub-objectives:

O1: Drafting educational models of Highly Effective

Learning.

$\mathrm{O} 2$ : Verifying the effectiveness of the proposed educational models experimentally.

O3: Evaluating and interpreting the results.

\section{Research Stages}

1. The creation of the annual topic, which includes the educational components of the elementary school thirdgrade subjects.

2. Preparation of measuring devices for the implementation of input measurements.

3. Implementation of (input) pre-measurements

4. Implementation of experimental verification of the HE Learning educational model in educational practice.

5. Implementation of (output) post-measurements.

6. Quantitative and qualitative analysis of measurement results and their interpretation.

7. Generalizations and conclusions for pedagogical theory and practice.

\section{Research Hypotheses}

H1: Through the HE Learning educational model, the pupils from the experimental group will achieve a more significant improvement of the knowledge level compared to the control group.

H2: The implementation of the HE Learning model will lead to a more significant increase in the level of creativity in the experimental group than in the control group.

H3: The application of the HE Learning model in experimental classes will contribute to a statistically significant improvement in the social climate compared to the control group.

\section{E. Research Methods}

The choice of relevant research methods is essential to ensure the quality of research and the soundness of its results. The research project used methods that can be divided into three groups:

\section{1) Experimental Research Preparation Methods}

This group of methods includes the study of expert literature and pedagogical documentation (books, 
periodicals, electronic media, curricula, methodological manuals, textbooks and workbooks, educational standards for the elementary school first-grade, and time-thematic plans for elementary school third-grade) and the creation and sorting of excerpts.

\section{2) Educational Process New Data Collection Method}

\section{a) Pedagogical Experiment}

An experiment is a universal method aimed at establishing patterns in the occurrence of phenomena. Its peculiarity is that it answers not only the question of how phenomena are related to each other, but especially the question of what causes this connection [7]. The premise thereof, as stipulated by Ondrejkovič (2015), is empiricism, evoked and acquired by deliberate actions in an induced situation. Here we manipulate with one or more variables (e.g., the HE Learning model) and monitor and control their impact on other dependent variables (e.g., the effectiveness of education). The system of the experimental method requires a pre-test (input), which precedes the experiment itself, and a post-test (output), which comes at the end of the experiment. The experiment is performed in the experimental group by manipulating the independent variable, and the results are compared with the control group of subjects, where the independent variable was not manipulated (Ondrejkovič, 2005).

According to (Skalka \& Skalková, 2013) the experiment does not stand out as an isolated method. It is usually used as the principal method, but it is also combined with other methods, such as a questionnaire, observation, interview, or testing.

In line with the goal and hypothesis verification, the researchers used the following measuring instruments:

a) Didactic test (omnibus) — a measuring instrument for objective measurement of the effect in an educational environment. It represents a task, or a series of tasks, the solution to which provides information on the property measured and the level of the examinee synthesizing learning tasks of several subjects.

b) Urban Figural Test of Creative Thinking (TSD-Z) - a screening tool providing an objective view of an individual's creative potential. It is characterized by a wide range of uses, igniting the possibility of identifying extremely high creative abilities, as well as detecting individuals with below-average developed creative abilities, which, however, can be developed and improved. The test consists of two test sheets (A and B) containing figural fragments for illustration and applies individually and collectively in subjects from four years to late adulthood.

c) My Class Inventory - a sociometry tool focused on data collection in five segments:

- class satisfaction - pupils' relationship to their class, level of satisfaction,

- classroom conflicts - complications in pupils' relationships in the classroom, degree antipathies and disagreements,

- classroom competition - competitive relationships between pupils, the degree of attempts to excel, experiencing school failures,

- learning demands - experience the school's demands on pupils,
- class cohesion - friendly and hostile relations between pupils, degree of class cohesion.

d) Direct observation - focused on the immediate and deliberate perception of educational phenomena and processes.

e) Non-standardized interview - answers collection method through interactive verbal interview.

f) Analysis of products of student activity.

\section{3) Data Analysis Method}

Mathematical and statistical methods allow accurate quantification of research results. Various statistical tests are used for statistical verification of hypotheses, analyzing the significance of differences in mean values, i.e., the differences between various groups.

The following statistical tests were used as an evaluation tool in hypothesis testing:

a. Mann-Whitney U Test - is considered the most sensitive nonparametric alternative to the t-test for independent samples. The test interpretation is essentially identical to the interpretation of the t-test result for independent samples, with the difference that the $U$ test compares the sums of the relevant sequences instead of the mean values.

b. Wilcoxon Paired Samples Test - serves to verify the hypothesis about level agreement in two sets from which paired (dependent) selections were made. This is a nonparametric analogy of a paired t-test.

c. We use Statistica, the computer statistical program for statistical data processing.

\section{F. Sampling}

To objectify the research plans, the location of the sample is determined to be eastern Slovakia, and the basic sample group comes from Košice Self-Governing Region (Slovakia). The selection of this location was mainly based on the high concentration of the Roma population, which is undoubtedly reflected in the percentage of Roma pupils in many, especially rural, elementary schools. A sample was created from the basic group by a deliberate selection, which consisted of rural as well as urban elementary schools with Roma classes in the target region.

The research sample consisted of 406 Roma pupils. Experimental classes (10 classes) and control classes (10 classes) consisted of 204 and 202 pupils respectively. The research was conducted in 2020/2021 as replica research from 2007.

\section{RESULTS}

The first step in pedagogical research is the collection of research material. The information collected is further analyzed and evaluated in two levels:

1. Quantitative (descriptive);

2. Qualitative (explanatory).

The mutual synthesis of these levels leads to a significant increase in the scientific level of research of pedagogical phenomena (Darák \& N. Krajčová, 2020). To verify the hypotheses established based on the facts presented, we disclose the analysis of the data collected vis-a-vis both levels stated.

The research aimed to experimentally verify the 
effectiveness of the HE Learning model for increasing the effectiveness of education of elementary school Roma pupils The operationalization of the research plan was expressed in the following hypotheses:

H1: Through the HE Learning educational model, experimental group pupils will achieve a more significant improvement of the knowledge level compared to the control group.

H2: The implementation of the HE Learning model will lead to a more significant increase in the level of creativity in the experimental group than in the control group.

H3: The use of the HE Learning educational model in experimental classes will contribute to a statistically significant improvement of the social climate compared to the control group.

To verify the H1 Hypothesis, we used a non-standardized didactic test - the omnibus test - which was applied on the post-measurement step following the methodological context of the pedagogical experiment. The didactic test consisted of two variants intended for pre-tests and post-tests, and the nature of the test (open, subjectively ranked) tasks corresponds to the requirements of the educational standards of the respective grade.

A detailed study of the data obtained through the pre-test and the post-test in both research groups shows (especially from the post-test) certain differences.

Note: the maximum score in both tests (pre and post) was forty-two points.

The data collected were rendered in graphical representation. At this point, however, we disclose a sample of the pre-test and post-test results in the first experimental group (class) $a_{1}$ and control $b_{1}$ (see Fig. 1 and Fig. 2) only.

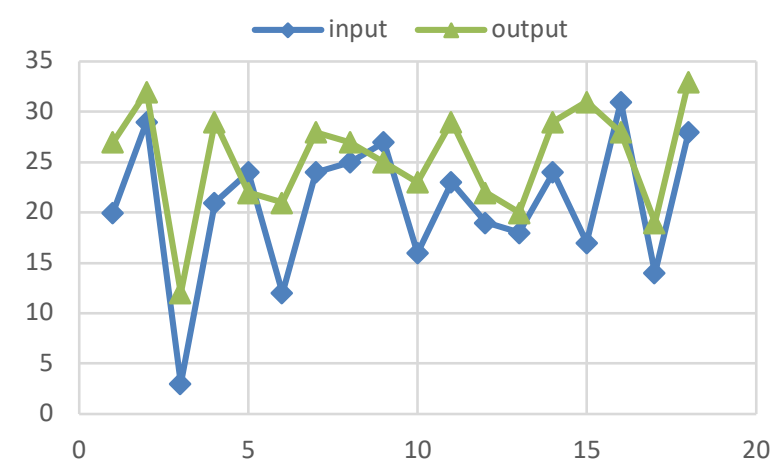

Fig. 1. Pre-Test \& Post-Test Graphical Representation $\left(\mathrm{a}_{1}\right)$ (Source: own elaboration).

For comparison, we present a graphical representation of the control test point scores achieved on the pre-test and posttest.

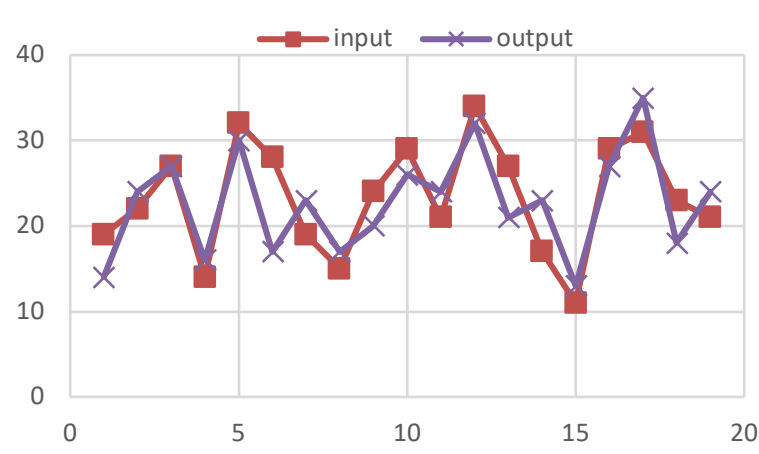

Fig. 2. Pre-Test \& Post-Test Graphical Representation (b1) (Source: own elaboration).

Following the statistical analysis of the test results in the sample experimental and control classes, we can conclude that the expected significant difference between the experimental and control group was observed. This significance was established by a nonparametric MannWhitney U Test at a level of $\mathrm{p}<0.05$ (See Table I).

TABLE I: DidACTIC PRE-TEST \& POST-TEST-EXPERIMENTAL GROUP AND CONTROL GROUP RESULTS STATISTICAL COMPARISON

\begin{tabular}{ccc}
\hline \hline Channels & p-value & $\begin{array}{c}\text { Statistical } \\
\text { Significance }\end{array}$ \\
\hline \hline Didactic test - pre-test & 0.3714 & $\mathrm{~N}$ \\
Didactic test -post-test & 0.02665 & + \\
\hline \hline
\end{tabular}

(Source: own elaboration)

The pre-test and post-test results in both research groups show that the H1 Hypothesis was confirmed.

To verify the H2 Hypothesis, we used the standardized Urban Figural Test of Creative Thinking (from the German original: Test zum Schöpferischen Denken-Zeichnerisch TSD-Z), which has several advantages over other creativity tests:

1. The use of the drawing modality significantly increases the level of the so-called culture-fair testing, which cannot be achieved in oral tests.

2. Unlike the "traditional" creativity tests, which are focused on quantity (Torrance Test of Creative Thinking) — on the factors of divergent thinking (e. g. fluence), TSD-Z also includes the qualitative features of creative performances. The qualitative degree of creative production is determined primarily by the questions of unconventionality and originality, multidimensionality, and crossing of boundaries, which are undoubtedly evident already in the analysis of test figural fragments.

3. The simplicity of administration and evaluation, the economics of use, and the wide applicability multiply the test multidimensionality (Urban et al., 2002).

With the method above, we performed pre-testing and post-testing of the level of pupils' creative potential. Each test was evaluated not only as a whole but also within its individual test sheets, which significantly contributed to a more comprehensive knowledge of the pre-test and post-level levels of the creative potential researched in both research groups.

A detailed study of the pre-test and post-test data in both research groups shows some differences.

Similar to the knowledge test results, we disclose the first experimental ( $\mathrm{x}_{1}$; see Fig. 3) and control ( $\mathrm{y}_{1}$; see Fig. 4) group 
(class) creativity test only.

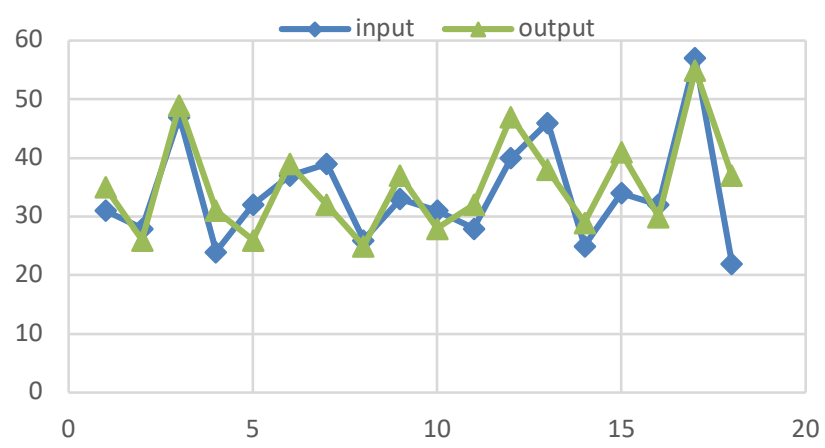

Fig. 3. Pre-Test \& Post-Test Graphical Representation ( $\mathrm{x}_{1}$ ) (Source: own elaboration).

For comparison, we present a graphical representation of the control test point scores achieved on the TSD-Z pre-test and post-test.

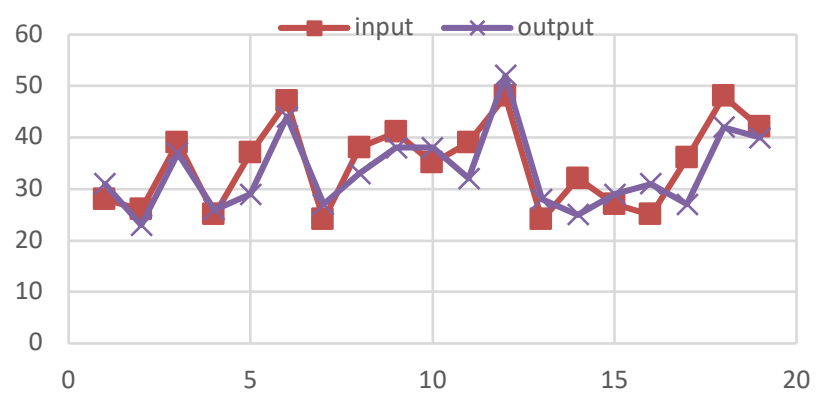

Fig. 4. Pre-Test \& Post-Test Graphical Representation ( $\left.\mathrm{y}_{1}\right)$ (Source: own elaboration).

Within the $\mathrm{H} 2$ Hypothesis and by comparing the results, it is possible to conclude that the score of the experimental group improved significantly from the pre-test to the posttest. This significant improvement was established by a nonparametric Mann-Whitney U Test at a level of $\mathrm{p}<0.05$ (See Table II).

TABLE II: DidACTIC PRE-TEST \& POST-TEST-EXPERIMENTAL GROUP AND CONTROL GROUP RESULTS STATISTICAL COMPARISON

\begin{tabular}{ccc}
\hline \hline Channels & p-value & $\begin{array}{c}\text { Statistical } \\
\text { Significance }\end{array}$ \\
\hline \hline TSD-Z Pre-Test & 0.2355 & $\mathrm{~N}$ \\
TSD-Z Post-Test & 0.0374 & + \\
\hline \hline (Source: own elaboration) & &
\end{tabular}

In the statistical evaluation of the $\mathrm{H} 2$ Hypothesis, a statistically significant difference was found between the results of the experimental and control groups, which confirmed the $\mathrm{H} 2$ Hypothesis.

A standardized test of creativity - Urban Figural Test of Creative Thinking - consists of two test sheets (A, B) applied in short succession, containing six fragmented pictures for the subjects to finish the drawing (see appendices). An additional but key element of the test is the square frame. This boundary is mainly used to find out information on the components of the 'willingness to take risks in the form of crossing borders. We evaluated the drawing according to fourteen categories representing the test construct.

The first category is the use of fragmented pictures. From a point of view of elements complexity, it can be concluded that several pre-test elements were lacking in both research groups. In particular, the incorporation of the element marked outside the square frame was absent. The post-test was more varied and complex in terms of the use of elements, especially in the experimental group. The implementation of fragments was more complex in this case.

Post-test finish drawing of elements was rather stereotypical. The elements were in most cases supplemented by graphical lines crossing the lines of the given fragment. The research field did not show any significant shortcomings in this area. In terms of the post-test, the pupils' output was richer and more detailed in this area, especially in the experimental group. Several graphic lines came from the given elements, which provided optical magnification of the element. The quality level was pronounced in this case.

The use of new elements - separate figures, independent of the fragments - was richly quantitatively represented, both in the experimental and control groups on the post-test. Pupils created several different elements, which, however, were repeated in many cases (e.g., the star). A similar situation, but with a more quantitative difference in favor of the experimental group, was observed on the post-test. The test sheets contained a number of new, non-repeating elements with a balanced distribution over the area.

The area of the fragments' graphical associations was in most cases without significant shortcomings in all research groups. According to the test construct, we evaluated the number of associations (not the number of associated elements). Associations between the out-of-frame element with other fragments were absent. We recorded the results above in both tests (pre and post-tests).

The thematic association of individual fragments was the most significant category in both research groups in the pretest. Based on the analysis of pupil productions, it can be stated that the elements included in a single composition reflect the understanding and relationship of objective reality and the implementation thereof in the children's world. We observed a more varied thematic continuity in the experimental group on the post-test, which undoubtedly stems from the real-world experiences, which are saturated with education according to the ITV model. In some cases, the individual components were also created by individual supplemented elements based on the expression and atmosphere mutually interconnected.

The dimension of crossing the boundary dependent on the figure consisted in drawing an element outside the square frame. The analysis of the pre-test results revealed only isolated cases of the use of these elements by the pupils from both research groups. However, the analysis of post-test results revealed a quantitative predominance of the use of the element by the pupils from the experimental group.

Crossing the border independent of the figure seems to be significantly problematic. The pupils' results in the pre-test did not contain almost any elements/figures that would be drawn outside a square frame. The opposite - although not a significant - situation occurred on the post-test, where we observed results in the experimental group containing just the elements exceeding the square frame. When we analyzed the results, we also considered whether the graphic exceedance is not the effect of graphomotor 'clumsiness', chance, or 
inattention. We can conclude that pupils have a willingness to take risks and the ability to overcome stereotypes.

The area of perspective was observed rather sporadically on both the pre-test and the post-test. Pupils of both research groups created mostly two-dimensional compositions with thematic continuity. The understanding of perspective as such was significantly absent, but the coverage of space defined by the frame was rich and typical of a two-dimensional representation.

Reactions to several drawings evoked a smile, and thus the category of humor, affectivity, emotionality, and expressiveness was strongly represented on both tests. It was evoked mainly by humorously drawn and combined elements. This category is to some extent subject to a subjective evaluation by the assessor.

The area of unconventionality synthesizes four variables: unconventional material manipulation (e.g., rotating a test sheet), abstraction, fiction, symbolism (e.g., use of ornaments), a combination of figures and symbols (e.g., the use of words, numbers, symbols), and non-stereotypical use of fragments. The variables above were not significantly represented in any of the research groups. Post-test results already contained some of these variables, but their quantity and representation in the composition speak in favor of the experimental group. Pupils mainly used words (e.g., ambulance) or symbols (e.g., cross).

The authors believe that the time factor, i.e., the drawing time, is included in the evaluation only if the drawing reaches a certain artistic level. It is deemed as an insignificant factor in group testing. Since this was the case here, we did not include this factor in the assessment.

The criteria above — whereby we assess individual drawings - provided the value of estimating the creative abilities of an individual by aggregation. The result provides an insight into the willingness to deal freely and flexibly with the task, creative attitudes, and openness to unusual and original meaningful content and solutions.

Lastly, it can be concluded that the implementation of the HE Learning model within the experimental group conditions had a positive impact on the development of pupils' creativity.

To verify the H3 Hypothesis, we used the sociometry questionnaire My Class Inventory, which is focused on data collection in five categories: classroom satisfaction, conflicts, competitiveness, learning complexity, and class cohesion. The questionnaire was - within the framework of the H3 Hypothesis - applied as part of the post-test.

Note: The achievable score in each category of the questionnaire ranged from five to fifteen points. In terms of data evaluation, it should be noted that in the segments of conflict, competitiveness, and learning complexity, the lower the score, the better the result.

To graphically display the data obtained, we calculated the value of the arithmetic mean of the data in each of the questionnaire categories, given the number of categories and the data collected in this manner. The data adjusted thusly can be converted into a graphical form (see Fig. 5 and Fig. 9).

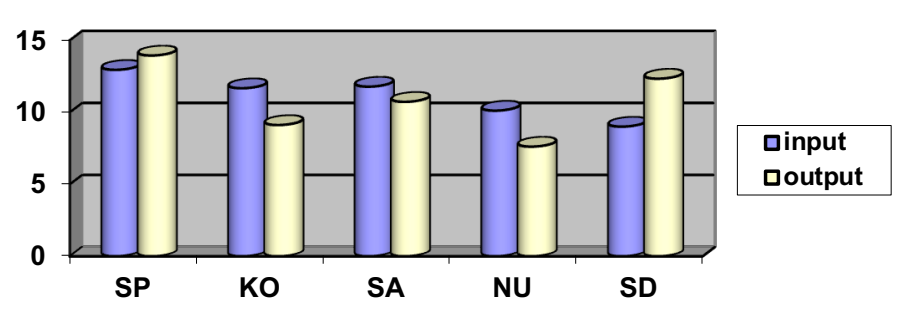

Fig. 5. Experimental Group 1 Pre-Test \& Post-Test Graphical Display (Source: own elaboration).

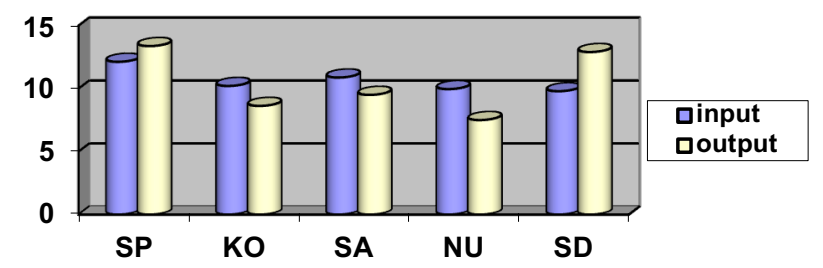

Fig. 6. Experimental Group 2 Pre-Test \& Post-Test Graphical Display (Source: own elaboration).

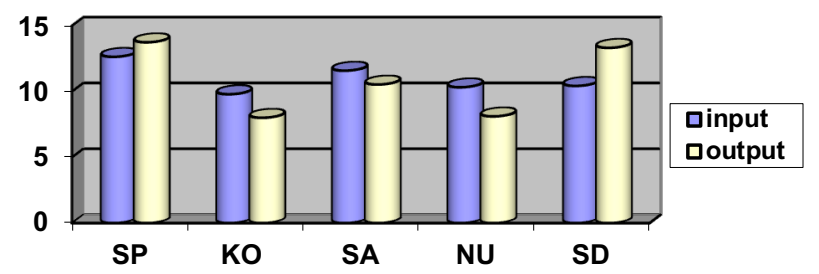

Fig. 7. Experimental Group 3 Pre-Test \& Post-Test Graphical Display (Source: own elaboration).

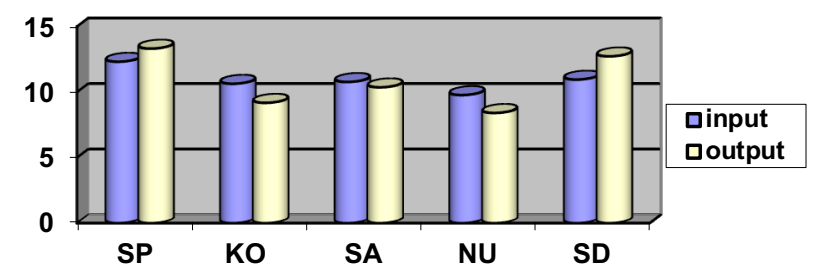

Fig. 8. Experimental Group 4 Pre-Test \& Post-Test Graphical Display (Source: own elaboration).

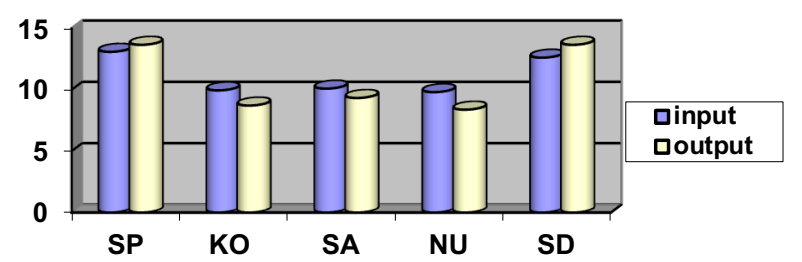

Fig. 9. Experimental Group 5 Pre-Test \& Post-Test Graphical Display (Source: own elaboration).

Graph Legend (\#5-9):

SP-Class Satisfaction

KO-Conflicts

SA-Competitiveness

NU_Learning Complexity

SD-Class Cohesion

Following the statistical analysis of the pre-test and posttest results of the level of pupils' social relations, it can be concluded that the H3 Hypothesis was confirmed. Statistical significance was determined by a nonparametric Wilcoxon Paired Test at a significance level of $\mathrm{p}<0.05$ (see Table III). 


\begin{tabular}{|c|c|c|}
\hline Channels & p-value & $\begin{array}{c}\text { Statistical } \\
\text { Significance } \\
\end{array}$ \\
\hline $\begin{array}{l}\text { SP on the } \\
\text { input/output }\end{array}$ & 0.02924 & + \\
\hline $\begin{array}{l}\text { KO on the } \\
\text { input/output }\end{array}$ & 0.03283 & + \\
\hline $\begin{array}{l}\text { SA on the } \\
\text { input/output }\end{array}$ & 0.08631 & $\mathrm{~N}$ \\
\hline $\begin{array}{l}\text { NU on the } \\
\text { input/output }\end{array}$ & 0.0370 & + \\
\hline $\begin{array}{l}\text { SD on the } \\
\text { input/output }\end{array}$ & 0.0175 & + \\
\hline
\end{tabular}

(Source: own elaboration)

Note: In the competition category in the experimental group, the expected decrease in the score was not observed.

When we compare the results, it is important to disclose the statistical analysis of the pre-test and the post-test of the level of social relations in the control group (see Table IV).

TABLE IV: SigNiFiCANCE OF CONTROL GROUP PUPILS SOCIAL RELATION LEVELS TEST RESULTS

\begin{tabular}{ccc}
\hline \hline Channels & p-value & $\begin{array}{c}\text { Statistical } \\
\text { Significance }\end{array}$ \\
\hline $\begin{array}{c}\text { SP on the } \\
\text { input/output }\end{array}$ & 0.0804 & $\mathrm{~N}$ \\
\hline $\begin{array}{c}\text { KO on the } \\
\text { input/output }\end{array}$ & 0.3712 & $\mathrm{~N}$ \\
\hline $\begin{array}{c}\text { SA on the } \\
\text { input/output }\end{array}$ & 0.4911 & $\mathrm{~N}$ \\
\hline $\begin{array}{c}\text { NU on the } \\
\text { input/output }\end{array}$ & 0.3520 & $\mathrm{~N}$ \\
\hline $\begin{array}{c}\text { SD on the } \\
\text { input/output }\end{array}$ & 0.2355 & $\mathrm{~N}$ \\
\hline \hline (Source: own elaboration)
\end{tabular}

(Source: own elaboration)

In the class satisfaction category, the data collected are mostly within the normal values (10-13). On the post-test, the score was higher by an average of two points in the experimental group, which points to the fact that the model under assessment has a positive effect on the pupils' class relations, satisfaction, and well-being.

Another category examined is class conflicts. The data obtained are within the normal range (7-13). On the post-test, the experimental group showed the desired decrease in the score by an average of three points. This points to the positive influence of the educational model on the reduction of complications and the degree of tension in pupils' relationships. When we assessed the individual post-test questionnaire items, we observed several ambiguous answers (pupils marked both answers YES and NO), which to some extent indicates a lack of opinion. However, due to the experimental effect, this changed significantly and progressively on the post-test of the experimental group. A less significant change also occurred in the control group (possible effect of the so-called maturation). However, this fact did not affect the test results.

As in the previous cases, the results in the class competitiveness category are within the normal range (1115). When we compared the pre-test with the post-test results, no significant change was observed in the score of the experimental group, which points out to the fact that the experimental effects did not have a significant impact on reducing the rate of attempts to excel and competitive relationships between pupils. This fact showed up with statistical significance. No changes occurred in this category in the control group similarly.
Particularly important (in terms of our research) is the learning complexity category, wherein the question of finding out how students tackle school challenges and how difficult is learning to them is assessed. Data obtained on the pre-test and post-test are within the normal range (6-11). We observed the expected decrease in the score on the post-test of the experimental group by an average of two points. This finding needs to be understood in a broader context, i.e., within all school subjects. The experimental effects were therefore of a broad-spectrum and complex nature.

The last of the examined category is the class coherence, where the data collected are within the normal range (6-13), as was the case in previous categories. This is the category where the largest increase was observed by an average of four points on the post-test. The control group did not show such a significant increase. Rather fluctuating results ( \pm one point) were represented here. Friendly and hostile reaction and the degree of class cohesion significantly deepened due to experimental effects (with the exception of hostile reactions, which we normalized), the classes became more cohesive societies with a predominance of positive social manifestations.

\section{Results And Recommendations for PedAgogical PRACTICE}

The educational blocks were implemented on elementary school third-grade Roma pupils with varying levels of knowledge and communication skills. The intention was to support new creative approaches in the elementary education of Roma pupils and to promote a change in common stereotypes and to increase efficiency and diversify the work of teachers and pupils.

Experimental verification of the effectiveness of the proposed educational blocks brought a lot of new knowledge. The most important is the following findings:

- The proposed highly effective educational blocks were implemented in elementary schools with the traditional way of teaching, and therefore, it was possible - especially in the beginning - to observe certain shortcomings in independent and creative activities or cooperation of pupils:

- pupils initially 'confirmed' each solution to the teacher,

- they were a little shy, especially in communities or other emotionally challenging activities,

- pupils gradually adapted, and over time, this phenomenon did not reoccur.

- During individual sessions with pupils, they became 'teachers of themselves (which is also the premise of one of the brain-conscious components of the HE Learning model, i.e. perfect mastery of the curriculum) and designed, compared, drew conclusions, and acquired new knowledge through their own creative activities.

We verified the facts above through informal interviews with pupils and teachers of experimental classes, which undoubtedly increased their soundness. We wanted to get more data about their opinions on the content, the analysis method, and the actual implementation of individual highly efficient blocks. The analysis of the interviews indicated that:

- The source of motivational charge in the pedagogical practice of the HE Learning model applied was mainly its practicality, pragmatism, interthematics, and 
interdisciplinarity, as well as the innovativeness of the educational system.

- Experience from the research indicates that the implementation of such an innovative system of education in the current conditions of Slovak education is not easy. The execution of the HE Learning model on a more massive scale would require more radical changes, both in material and organizational areas, as well as in human resources. It is about the professional potential and competencies of teachers in the context of highly effective learning. Nevertheless, the present model proved to be a very suitable and effective alternative in the elementary school current situation of Roma pupils.

\section{REFERENCES}

Brestenská, B. et al. (2019) Inovácie a trendy prírodovedného vzdelávania (Science Education Innovations \& Trends), Bratislava: PrF Commenius University, [online]. 21(10).

Darák, M. \& Krajčová, N. (2020) Základy empirického výskumu v pedagogike (Pedagogy Empirical Research Fundamentals). $3^{\text {rd }}$ Ed. Košice: P. J. Šafárika University, Slovak.

Kovalik, S. \& Olsen, K. D. (1996) Integrované tematické vyučovanie (Integrated Thematic Instruction). Bratislava: Faber, Slovak.

Ondrejkovič, P. (2005) Úvod do metodológie sociálnych vied - Základy metodológie kvantitativneho výskumu (Introduction to Social Science Methodology_Fundamentals of Quantitative Research Methodology). Bratislava: Regent, Slovak.

Urban, K., Jellen, H., Kováč, T. (2002) Urbanov figurálny test tvorivého myslenia (TSD - Z) - Príručka (Urban Figural Test of Creative Thinking (TSD - Z)—Handbook). Bratislava: Psychodiagnostika (Psychodiagnostics), Slovak.

Skalka, J. \& Skalková, J. (2013) Empirické výzkumy v pedagogice (Empirical Research in Pedagogy). $3^{\text {rd }}$ Ed. Praha: Charles University, Czech.

Švec S. (1998) Metodológia vied o výchove (Methodology of Educational Sciences). Bratislava: IRIS, Slovak.

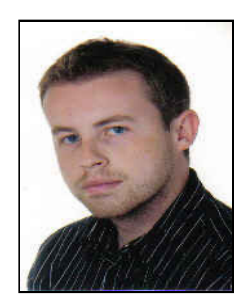

Michal Pankevič is an assistant professor at the Department of Preschool and Elementary Pedagogy, Faculty of Education, Catholic University in Ružomberok (Slovakia). It deals with the issue of alternative education, pupils' education from socially disadvantaged environment, multiculturalism, and its implementation in the educational process. His area of professional interest saturates the issue of educational historiography as well. 